\title{
Impact of the smell loss on the quality of life and adopted coping strategies in COVID-19 patients
}

\author{
Safaa Mostafa Ali Elkholi ${ }^{1} \cdot$ Mohamed Kamal Abdelwahab $^{2} \cdot$ Marwa Abdelhafeez $^{3}$ (i)
}

Received: 16 October 2020 / Accepted: 14 December 2020 / Published online: 19 January 2021

(c) The Author(s), under exclusive licence to Springer-Verlag GmbH, DE part of Springer Nature 2021

\begin{abstract}
Purpose To study the impact of smell loss on quality of life in patients with Coronavirus Disease 2019 (COVID-19), and assess the importance of olfaction before and after the loss of smell. In addition, to assess the impact of smell loss on psychological well-being and distress, and to assess coping strategies used by COVID-19 patients with smell loss.

Methods This study was a cross-sectional study. A total of 487 COVID-19 positive patients with anosmia were recruited. All participants filled in the validated Multi-Clinic Smell and Taste Questionnaire, and the validated General Well-being Schedule.

Results Negative impacts of smell loss, associated risks, interference with daily activities, and deterioration in well-being were common. The importance of the sense of smell was evaluated (In relation to other senses) as higher in the period after the loss than before the loss $(p<0.001)$. All aspects of health-related QOL are statistically significant $(p<0.001)$, with the exception of financial security and friendship, which are not statistically significant $(p=0.129, p=0.334)$, respectively. Psychological well-being was negatively affected, and the use of both problem- and emotion-focused strategies was common. Conclusion COVID-19 Patients with loss of smell have significant reductions in health-related QOL. Their loss of smell directly affects daily activities related to the olfactory function. Therefore, priority should be given to diagnose and treat the loss of smell. Patients who have recently developed smell loss may be offered a combination of the problem- and emotionfocused strategies to cope with their condition.
\end{abstract}

Keywords COVID-19 $\cdot$ Smell $\cdot$ Quality of life $\cdot$ Olfaction $\cdot$ Coping

\section{Introduction}

Coronaviruses (Co-Vs), which include Severe Acute Respiratory Syndrome (SARS-CoV-2), are the principal cause of the existing pandemic of coronavirus disease 2019 (COVID19) and have a predilection for neuro-invasion. Olfactory neurons are presently being researched as a portal of entry and spread of Co-Vs through a trans neural route [1]. The

Marwa Abdelhafeez

Marwaabdelhafeez@yahoo.com

Safaa Mostafa Ali Elkholi

smelkholi@pnu.edu.sa

1 Rehabilitation Sciences Department, Faculty of Health and Rehabilitation Sciences, Princess Nourah bint Abdulrahman University, Riyadh, Saudi Arabia

2 Faculty of Engeneering, Cairo University, Cairo, Egypt

3 Department of Otorhinolaryngology, Faculty of Medicine, Minia University, Minia, Egypt human strains of Co-Vs have been demonstrated to attack the central nervous system through the neuroepithelium and spread from inside the olfactory bulb [2].

SARS-CoV-2 affects people of all ages and genders. The symptoms range from asymptomatic to lethal infection [3]. Recently, olfactory and gustatory dysfunctions have been established to be related to COVID-19 infection. Now, in ambulatory populations, patients who complain of anosmia and influenza-like symptoms are six to ten times more likely to test positive for a COVID-19 infection [4]. This olfactory dysfunction is due to the direct destruction of the olfactory epithelium, which prohibits odours from binding to olfactory receptors in the olfactory epithelium [5]. Certainly, Xie et al. and Sutton et al. investigated the prevalence of smell and taste loss in COVID-19 positive patients and found that the prevalence is highly variable, ranging between 5 , and $48 \%[6,7]$. Because of the benignity of the symptoms, under-reporting was likely to occur. In addition, other studies 
have declared that the prevalence of smell and taste loss in COVID-19 positive patients is $59-86 \%[8,9]$.

Sense of smell is an essential chemical alarming system that regulates the intake of food and is participated in interpersonal relations. Unfavourable effects in patients with olfactory loss have been reported, including decreased pleasure in food, poor appetite, trouble with cooking and detecting spoiled food, alteration in body weight, reduced safety, doubts about personal hygiene, feelings of vulnerability, mood changes, depression and deterioration in social interactions, work life and sexual life [10]. Patients with olfactory loss disclose difficulties in everyday activities and a decrease in the quality of life (QOL) as a result of the loss of smell [11].QOL is the level of well-being felt by a group of people or an individual or, 'the functional impacts of sickness and its treatment upon a patient, as recognized by the patient himself' [12].

Olfactory deprivation for a month may be not serious. But if the deprivation lasts more than two months, it starts to become a problem. If the loss of smell persists for a long time, the QOL is affected. Olfactory loss in COVID-19 patients is usually severe and sudden, but it is temporary in most patients, although $10.6 \%$ of patients do not recover within one month [13]. Hufnagl et al. established negative effects in the enjoyment of food, personal hygiene, matters of safety, mood, sexual life and social interaction in patients with smell loss [14]. Therefore, coping strategies have played a key role in dealing with ordinary disorders and problems, mainly in patients with loss of smell, since treatment is limited or non-existent [15].

Therefore, the study aims to investigate the impacts of smell loss in COVID-19 patients in relation to QOL, and to assess the importance of olfaction before and after the loss of smell. In addition, to assess the impact of smell loss on psychological well-being and distress, and coping strategies used by COVID-19 patients with smell loss.

\section{Methodology}

\section{Study design and subjects}

The current study was a cross-sectional study utilizing an online self-reported questionnaire survey that was conveyed through: emails, shared in faculties official pages, and social media platforms (e.g., Facebook TM, WhatsApp and, Twitter $^{\mathrm{TM}}$ ). Data were collected from July 13th until September 8 th, 2020. The participants of this study were 487 COVID19 positive patients with loss of smell. Investment in the online questionnaire was intentional and participants had no compensation.

The inclusion criteria established for this research are:
1. Patients with a positive diagnosis of COVID-19, confirmed by PCR results, manifested by anosmia lasting more than two months.

2. Patients with a subjective scale of the olfactory function 0 points.

3. Age more than 18 years old.

4. Ability to read and understand questions as the survey was distributed electronically.

The exclusion criteria are:

1. COVID-19 patients without loss of smell.

2. Any other manifestation of COVID-19 besides the loss of smell.

3. People with a loss of smell for reasons other than COVID-19.

4. Patients with parosmia and/or phantosmia.

5. Patients below 18 years old.

6. Patients with known chronic conditions or disabilities (physical or mental) that affect QOL.

The questionnaire ended automatically if the participant did not meet the inclusion criteria or had the exclusion criteria using branching logic. Initially, the questionnaire was pilot tested on a group of 20 patients to assess the comprehension, content and clarity of the questionnaire.

\section{Procedure}

Researches prepared online questionnaire survey forms that consist of many sections. The first section includes sociodemographic information to determine the age and gender, if their smell loss due to COVID-19, and the threshold values for impairment of subjective olfactory functioning, that were assessed on an 11-point scale from 0 (no smell) to 10 (the best possible) [11]. The second section consists of questions from the Multi-Clinic Smell and Taste Questionnaire [16] that incorporates (1) questions to evaluate self-revealed anosmia, besides questions related to the outcomes of smell loss (Table 1). (2) questions concerning the importance of the sense of smell (Table 2), these were appraised on a 6-point scale extending from 0 (No importance) to 5 (Very large importance). (3) questions regarding QOL (Table 3), these questions include, 'How significant are the following aspects for your QOL: physical health, work-life, financial security, partnership, friendship, leisure, and emotional stability?' Each point had to be valued on a 6-point scale from 0 (not at all important) to 5 (very important), and also involve, 'How much has the loss of smell affected the related parts of your QOL: physical health, work-life, financial security, partnership, friendship, leisure, and emotional stability?' Each answer was to be valued on an 11-point scale from 
Table 1 Questions and responses (\%) about selfreported anosmia, as well as questions pertaining to the consequences of smell loss

\begin{tabular}{|c|c|}
\hline Question & Response (\%) \\
\hline \multicolumn{2}{|c|}{ Has the quality of your life declined in general since you lost your sense of smell? } \\
\hline Yes & 76 \\
\hline No & 24 \\
\hline \multicolumn{2}{|c|}{ Has your smell loss had any negative effects? If so, what is the most negative effect? ${ }^{\mathrm{a}}$} \\
\hline Less aware of personal hygiene & 38 \\
\hline Less interested in food and drink & 23 \\
\hline Less appreciation of nature & 2.9 \\
\hline Poorer quality of life in general & 3.7 \\
\hline Unable to perceive fire/smoke & 3.5 \\
\hline Less emotional satisfaction & 0.6 \\
\hline General feeling of uncertainty & 1.2 \\
\hline Less satisfied with the profession & 0.4 \\
\hline \multicolumn{2}{|c|}{ Has your smell loss had any positive effects? If so, what is the most positive effect? ${ }^{\mathrm{a}}$} \\
\hline No longer bothered by unpleasant odors & 20.7 \\
\hline Have no need to buy perfume & 2.9 \\
\hline \multicolumn{2}{|c|}{ Do you perceive any risks associated with your smell loss? } \\
\hline \multicolumn{2}{|c|}{ If so, what is the main risk $?^{\mathrm{a}}$} \\
\hline Failure to perceive fire/smoke & 53.5 \\
\hline Failure to perceive rancid/ill-smelling food & 14.2 \\
\hline Failure to perceive dangerous chemicals/gases & 5.2 \\
\hline \multicolumn{2}{|l|}{ Does your smell loss interfere with your daily activities? } \\
\hline \multicolumn{2}{|l|}{ If so, what is the main type of interference? $?^{\mathrm{a}, \mathrm{b}}$} \\
\hline Difficulties in cooking & 24.5 \\
\hline Problems with eating & 14.6 \\
\hline Feel obliged to wash myself/my home more often & 2.7 \\
\hline Difficulties in using perfume/after shave & 2.5 \\
\hline Need to change leisure/spare-time activities & 0.8 \\
\hline Reduced ability to do professional work & 0.9 \\
\hline Seek clean air more often & 2.1 \\
\hline Difficulties in mixing with friends & 0.8 \\
\hline \multicolumn{2}{|c|}{ Has your smell loss affected your well-being? If so, what is the main effect? ${ }^{a, b}$} \\
\hline Depression & 15.8 \\
\hline Poorer general well-being & 5.6 \\
\hline Irritability & 3.6 \\
\hline Asthmatic reactions more often & 1.1 \\
\hline \multicolumn{2}{|c|}{ How has your smell loss affected your ability to taste/enjoy food? ${ }^{\text {b }}$} \\
\hline Improved & 2.7 \\
\hline No change & 10.9 \\
\hline Diminished & 84.6 \\
\hline \multicolumn{2}{|l|}{ How has your smell loss affected your appetite? ${ }^{\mathrm{b}}$} \\
\hline Improved & 3.1 \\
\hline No change & 30.4 \\
\hline Worsened & 66.5 \\
\hline
\end{tabular}

${ }^{\text {a } O p e n-e n d e d ~ q u e s t i o n ~}$

${ }^{b}$ Evaluated regarding comprehension and reliability [16]
- 5 (very extensive deterioration), to 0 (no change at all) to 5 (very extensive improvement). The Multi-Clinic Smell and Taste Questionnaire has been shown to have good test-retest reliability, internal consistency, validity [16].
The last section of the questionnaire consists of the General Well-Being Schedule (GWBS) [17]. That includes questions for evaluating psychological well-being and distress $\&$ questions about coping strategies with the smell loss. 
Table 2 Questions and responses (\%) about the importance of the sense of smell
Table 3 Questions and responses as medians (interquartile range) and $p$ value about aspects of health- related quality of life

(a) Has your view concerning the importance of your sense of smell changed since you lost your sense of smell? ${ }^{\mathrm{a}}$ If so, how?

It has become less important 3.1

It has become more important $\quad 87.7$

My opinion has not changed $\quad 9.2$

(b) How important did you think your sense of smell was in relation to your other senses (hearing, 4 vision, touch and taste) before you lost your sense of smell? (median) ${ }^{\mathrm{c}}$

How important did you find your sense of smell to be in relation to your other senses (hearing, $\quad 5$ vision, touch and taste) after you lost your sense of smell? (median) ${ }^{\mathrm{c}}$

${ }^{\mathrm{a} O p e n-e n d e d ~ q u e s t i o n}$

${ }^{b}$ Evaluated regarding comprehension and reliability[16]

${ }^{c}$ (b) The importance of the sense of smell was rated on a 6-point scale ranging from 0 , No importance, to 5 , very large importance

\begin{tabular}{lcc}
\hline Question & $\begin{array}{l}\text { Responses as median } \\
\text { (interquartile range) }\end{array}$ & $p$ value \\
\hline How important are the following aspects for your quality of life? & & \\
Physical health & $5.0(1.0)$ & $0.000^{*}$ \\
Financial security & $4.0(1.0)$ & $0.000^{*}$ \\
Work life & $3.0(2.0)$ & $0.025^{*}$ \\
Partnership & $3.0(1.0)$ & $0.000^{*}$ \\
Friendship & $3.0(1.0)$ & $0.036^{*}$ \\
Emotional stability & $4.0(2.0)$ & $0.033^{*}$ \\
Leisure & $4.0(1.0)$ & $0.030^{*}$ \\
To what extent has your smell loss affected the following aspects of & & \\
your quality of life? & & $0.000^{*}$ \\
Physical health & $-2.0(2.0)$ & 0.129 \\
Financial security & $0.0(1.0)$ & $0.000^{*}$ \\
Work life & $-1.0(3.0)$ & $0.000^{*}$ \\
Partnership & $-1.0(3.0)$ & 0.334 \\
Friendship & $0.0(3.0)$ & $0.000^{*}$ \\
Emotional stability & $-1.0(3.0)$ & $0.000^{*}$ \\
Leisure & $-2.0(3.0)$ &
\end{tabular}

${ }^{*} p<0.05$ :significant. $p \geq 0.05$ : nonsignificant

a Rated on a six-point scale ranging from 'not at all important, 0 ' to 'very important, 5'

${ }^{b}$ Rated on an 11-point scale ranging from 'very extensive deterioration, -5 ' to 'no change at all, 0 ', to 'very extensive improvement, 5 ,

The scores of GWBS ranges between 0 and 110 [It can be mentioned that patients have a 'positive wellbeing' (scores 73-110), a 'moderate distress' (scores 61-72), and a 'severe distress' (scores 0-60)]. It has been shown to have good test-retest reliability, internal consistency, validity [18] and it has normative data [19].

The GWBS includes five problem-oriented and six emotion-oriented questions about the use of coping strategies for the loss of smell, which were used with yes or no answers. Emotional strategies and problem- based information-seeking strategies are commonly used to deal with situations in general, while the other four problem-oriented strategies can be seen as specific to the loss of smell.

\section{Statistical analysis}

Data were analyzed by the Statistical Package of Social Science (SPSS), software version 26.0 (SPSS Inc., 2019). The normality of data distribution was checked using the Shapiro-Wilk $W$ test. Chi-square test was used to analyze data on psychological well-being and distress. One-sample sign tests were used to analyze the QOL data. Wilcoxon's matchedpairs signed-ranks test was used to analyze the importance of the sense of smell before and after the smell loss. The level of significance was set at 0.05 . 


\section{Ethical consideration}

All ethical considerations were completed before the study. Ethical approval from the Medical University Research Center has been requested (IRB No. 20-0264, July 13th, 2020). Informed consent was obtained before each participant answered the online questionnaire. Thus, potential participants were made aware of the purpose and the content of the study before entering the study. After being fully instructed and acknowledging the principle of anonymity and unlinking, along with other ethical considerations, they answered questions online out of their own accord. Consent was recorded electronically at the start of the survey, all participants agreed to the purpose of the survey and contributed to this online survey.

\section{Result}

\section{Baseline characteristics of the study group}

This study included 487 patients who tested positive for COVID-19 with anosmia. The study sample consisted of $370(76 \%)$ females and 117 (24\%) males. The average age was $31.4 \pm 9.7$ years.

\section{Consequences of smell loss}

Table 1 shows the distribution of answers about the effects of loss of smell. About $76 \%$ of patients noted a decrease in their QOL. The negative effects were reported by $73.3 \%$, who were most concerned about the attentiveness of personal hygiene, interest in food, and drinks. While the positive effects were reported by $23.6 \%$ who were not disturbed by unpleasant odors, and do not need to buy perfume. Answers to questions about associated risks were reported by $72.9 \%$ of patients, interventions of the loss of smell during daily activities were reported by $48.9 \%$, and the effect on wellbeing was reported by $26.1 \%$. When asked about food intake, $84.6 \%$ said their ability to taste or enjoy food had decreased, and $66.5 \%$ said their appetite had worsened.

\section{The importance of smell}

Table 2 shows that $87.7 \%$ of patients answered, that they became more concerned about the importance of smell after the loss. The importance of the sense of smell was evaluated (In relation to other senses) as higher in the period after the loss than before the loss, as evidenced by the Wilcoxon's matched-pairs signed-ranks test $[Z=-8.62, p<0.001]$.

\section{Impact of smell loss on QOL}

Table 3 shows the median (interquartile range) assessments of the importance of aspects of QOL, which suggests that all the seven aspects were important for QOL, as confirmed by one-sample sign tests. Table 3 also shows to what extent the loss of smell has affected these aspects of QOL. One-sample sign test shows that all aspects are statistically significant $(p<0.001)$, with the exception of financial security and friendship, which are not statistically significant $(p=0.129$, $p=0.334)$, respectively.

\section{Coping with loss of smell}

The mean \pm standard error of psychological well-being and distress on the GWBS scale were $69.73 \pm 20.98$. According to these estimates, $47 \%$ of patients were categorized as 'positive well-being' (scores 73-110), 23\% as 'moderate distress' (scores 61-72), and 30\% as 'severe distress' (scores 0-60). These percentages were compared with the standard data for the population [19], which are $71 \%, 15 \%$, and $14 \%$, respectively. Chi-square analysis gives a significant difference in the distribution of the three categories between patient and normative data $\left[\chi^{2}(2)=12.73, p<0.05\right]$.

The most common problem-focused strategy was to let a relative to taste food that might have been rotten (69.4\%), other strategies were, Do you ask a family member whether you have just enough perfume/aftershave? (49.7\%), have you looked for information about your smell loss? (33.3\%), Do you avoid meeting other people? (6\%), and Have you found solutions to problems caused by your smell loss? (6\%). The most common emotion-focused strategy was to try to accept the situation (61.4\%), other strategies were, Do you compare your problems with those who are worse off? (47.8\%), Do you try not to think about your smell loss? (23\%), Do you seek support from family members? (30\%), Do you try to concentrate on the advantages of your smell loss? (8\%), and Do you try to reprioritize how important different things are to you? $(7 \%)$.

\section{Discussion}

Smell loss significantly impacts patients' lives. It is difficult for the normosmic individual to imagine what life would be without the sense of smell [20]. Certain viruses such as rhinovirus, parainfluenza virus, and coronavirus (SARS-CoV-2) [21] can cause post-viral loss of smell via processes other than the obstruction of the olfactory clefts, indicating a certain affinity of these viruses for olfactory neuroepithelium [22]. To the best of our knowledge, there 
is no QOL literature related to the loss of smell in patients with COVID-19.

The results of this study indicate that the overall aspects of QOL deteriorate after the onset of smell loss, as $76 \%$ of the patients indicated. This percentage is higher than the $67 \%$ quoted by Blomqvist et al. [23] in their study. Concerning the effects of the loss of smell, this study discovered only the main effects, which are depicted in Table 1. Regarding the negative effects of the loss of smell, $38 \%$ of the patients chose 'less aware of own hygiene', as also noted by Temmel et al., Blomqvist et al., and Nordin et al. in $41 \%, 36 \%$ and $19 \%$ of their patients, respectively [23-25]. The second main negative effect is 'less interest in food and drink', which was indicated by $23 \%$ of the patients. 'Less interest in food and drink' was also reported by Blomqvist et al., Nordin et al., and Ferris et al. in 21\%, 15\% and 69\% of their patients, respectively [23, 25, 26]. 'No longer bothered by unpleasant odours' was considered the most frequent benefit, experienced by $20.7 \%$ of patients. However, the fact that most patients did not choose this option may be due to the realization that foul odours can be toxic or dangerous, and, therefore, it is important to perceive sensory warning through the sense of smell. Another study demonstrated that $38 \%$ of the patients chose 'no longer bothered by unpleasant odours' as the most frequent benefit [25].

Working again! The principal threat associated with the loss of smell is the inability to detect gas, fire, or smoke, which were symptoms indicated by $53.5 \%$ of the patients in this study. Additionally, Miwa et al., Blomqvist et al., and Nordin et al. stated that $61 \%, 42 \%$, and $38 \%$, correspondingly, of the patients were also unable to detect the fumes of gas, fire, or smoke [23, 25, 27]. In contrast, Haxel et al. reported that only $20 \%$ of patients stated that they were unable to detect smoke from a fire [28]. Nonetheless, these deficiencies in the ability to smell can affect patient safety and may cause a multitude of side effects that must be taken with caution in advance so as not to harm patients.

Regarding the disruption of daily activities, $24.5 \%$ of patients reported difficulties with the preparation of food and $14.6 \%$ reported troubles with eating. Although these struggles were not disclosed by all participants, these types of issues can affect an individual's level of independence, leading to occupational deprivation. This is especially true for mothers, housewives, and other individuals whose work may involve cooking. A decrease in the ability to taste and experience the enjoyment of eating, as noted with $84.6 \%$ of patients, resulted in a decrease in appetite in $66.5 \%$ of patients. A diminished desire for food was also reported by $32 \%, 27 \%$, and even $56 \%$ of the patients in other studies, respectively [23-25]. Complaints of taste loss in COVID19 patients are likely to reflect disruptions in the olfactory system, rather than disrupt the taste afferents or taste buds. Thus, the majority of people who clinically complain of loss of taste actually exhibit olfactory loss, including those with viral etiology [29]. Loss of appetite itself is considered a major issue, as it can lead to malnutrition and weakness, as well as affect the general health of patients. Depression was the most frequently disclosed symptom affecting well-being, which was reported by $15.8 \%$ of patients.

It can be concluded that COVID-19 patients with a loss of smell experience limitations in daily life and professional activities, the pleasure of food and drink, communication, intimate relationships, and even the perception of warning signals related to the ability to smell. Correspondingly, previous reports have also shown that patients with olfactory loss have problems in daily life circumstances relating to smell [30, 31].

This research focused on the importance of smell. The results clearly show that the sense of smell becomes more important after the loss of it, as reported by $87.7 \%$ of patients as shown in Table 2. This opinion is also supported by the assessment of smell in relation to other senses (sight, hearing, touch, and taste). Thus, continually concluding that the sense of smell was judged to be much more important after the loss than before as $(p<0.001)$ although this result should be interpreted carefully due to the reverse nature of both questions. Nevertheless, the results regarding the importance of smell are consistent with other studies [23, 25].

All participants in this study were united in the opinion that all seven aspects of health-related QOL are important $(p<0.05)$, as shown in Table 3. An assessment of healthrelated QOL using the Multi-Clinical Smell and Taste Questionnaire clearly demonstrated that COVID-19 patients with a loss of smell experienced significant effects on physical health, work-life, partnerships, emotional stability, and leisure $(p<0.001)$. Financial security $(p=0.129)$ and friendship ( $p=0.334)$, however, were not significantly affected. In line with this study, Blomqvist et al. stated that all aspects of health-related QOL were statistically significant, except for financial security [23]; Nordin et al. stated that all seven aspects were significantly affected [25]. There was no effect of age or gender on any of the aspects of health-related QOL. The lack of association between health-related QOL on age and gender was unexpected, due to the known effects of age and gender on olfactory function [32]. However, these results support previous research showing no effect of age and gender on aspects of QOL [33].

GWBS scores also show that psychological well-being (depression, anxiety, general health, self-control, wellness, and vitality) was negatively affected. This study found that $47 \%$ of patients reported positive wellbeing, $23 \%$ reported moderate distress, and $30 \%$ reported severe distress. Similarly, another study found $50 \%$ of patients with positive wellbeing, $20 \%$ with moderate distress, and $30 \%$ with severe distress [25]. Most patients developed a various problem and emotion-focused strategies to cope with their 
loss of smell, as shown in result section. Problem-based strategies that were often reported included 'let a family member taste the food' $69.4 \%$; 'check for too much perfume/aftershave' $49.7 \%$; and 'look for information about loss of smell' $33.3 \%$. Emotional strategies that were often reported included 'trying to accept the situation and get the most out of it' $61.4 \%$, 'comparing your problems with those who are worse off' $47.8 \%$, and 'Are you seeking social support from family members?' $30 \%$. These coping strategies have also been used by people with loss of smell in other studies $[23,25]$.

Taken together, the results of this study show that loss of smell in COVID-19 patients had a significant impact on QOL when it was associated with those situations or functions in which chemical senses play a significant role.

This study has some limitations. First, all collected data were self-reported. The inclusion of patients with loss of smell was based on self-attributed loss of smell. In most studies, individuals with a loss of smell were included after a test of olfactory function, often including an odouridentification test, showed a decrease in ability compared to age and gender norms. In addition, loss of smell in selfreported olfactory function may mean that it could be normal. Second, the apparent predominance of female (76\%) warrants further investigation, as this may simply reflect gender differences in the completion and dissemination of the survey. Third, only a small percentage in this study were over 60 years old $(0.4 \%)$, but this may reflect a selection bias regarding the type of people who will complete the online survey using email as a contact point or the high prevalence of pre-existing smell loss in this age group.

\section{Conclusion}

COVID-19 patients with a loss of smell have significant reductions in their health-related quality of life. Their smell deprivation directly affects daily activities related to olfactory functions. Therefore, priority should be given to the diagnoses and treatments of the loss of smell, especially when using an olfactory training program. Additionally, patients who have recently developed a loss of smell may be offered a combination of problem-focused as well as emotion-focused strategies to cope with their condition.

Acknowledgements This research was funded by the Deanship of Scientific Research at Princess Nourah Bint Abdulrahman University through the Fast-track Research Funding Program.

Author contributions MA conceived and designed the study, wrote the paper, participated in data analysis, and participated in reviewing, and revising the manuscript. SE collected the data, and participated in reviewing, and revising the manuscript. MKA analyzed the data.
Availability of data and material The authors confirm that the data supporting the findings of this study are available within the article.

\section{Compliance with ethical standards}

Conflict of interest The authors have no conflicts of interest to report.

Ethics approval All ethical considerations were completed before the study. Ethical approval from the Medical University Research Center has been requested (IRB No. 20-0264, July 13th, 2020).

Consent to participate Informed consent was obtained before each participant answered the online questionnaire. Thus, potential participants were made aware of the purpose and content of the study before entering the study.

Consent for publication The publication is approved by all authors, and that, if accepted, it will not be published elsewhere in the same form.

\section{References}

1. Li YC, Bai WZ, Hashikawa T (2020) The neuroinvasive potential of SARS-CoV2 may play a role in the respiratory failure of COVID-19 patients. J Med Virol 92:552-555. https://doi. org/10.1002/jmv.25728

2. Dubé M, Le Coupanec A, Wong AH, Rini JM, Desforges M, Talbot PJ (2018) Axonal transport enables neuron-to-neuron propagation of human coronavirus OC43. J Virol. https://doi.org/10.1128/ JVI.00404-18

3. Wu Z, McGoogan JM (2020) Characteristics of and important lessons from the coronavirus disease 2019 (COVID-19) outbreak in China: summary of a report of 72314 cases from the Chinese Center for Disease Control and Prevention. JAMA 323:12391242. https://doi.org/10.1001/jama.2020.2648

4. Yan CH, Faraji F, Prajapati DP, Boone CE, DeConde AS (2020) Association of chemosensory dysfunction and Covid-19 in patients presenting with influenza-like symptoms. Int Forum Allergy Rhinol 10:806-813. https://doi.org/10.1002/alr.22579

5. Murphy C, Doty RL, Duncan H J (2003) Handbook of olfaction and gustation. In: Richard L (ed) Clinical disorders of olfaction, 2nd edn. CRC Press, New York, pp 822-849. https://doi. org/10.1201/9780203911457.ch22

6. Xie J, Tong Z, Guan X, Du B, Qiu H, Slutsky AS (2020) Critical care crisis and some recommendations during the COVID19 epidemic in China. Intensive Care Med 2:1-4. https://doi. org/10.1007/s00134-020-05979-7

7. Sutton D, Fuchs K, Dalton M, Goffman D (2020) Universal screening for SARS-CoV-2 in women admitted for delivery. N Engl J Med 382:2163-2164. https://doi.org/10.1056/nejmc20093 16

8. Menni C, Valdes A, Freydin MB, Ganesh S, Moustafa JE, Visconti A, Hysi P, Bowyer RC, Mangino M, Falchi M, Wolf J (2020) Loss of smell and taste in combination with other symptoms is a strong predictor of COVID-19 infection. medRxiv. https://doi. org/10.1101/2020.04.05.20048421

9. Lechien JR, Chiesa-Estomba CM, De Siati DR, Horoi M, Le Bon SD, Rodriguez A, Chekkoury-Idrissi Y (2020) Olfactory and gustatory dysfunctions as a clinical presentation of mild-to-moderate forms of the coronavirus disease (COVID-19): a multicenter European study. Eur Arch Otorhinolaryngol 6:1-11. https://doi. org/10.1007/s00405-020-05965-1 
10. Hummel T, Nordin S (2005) Olfactory disorders and their consequences for quality of life. Acta Otolaryngol 125:116-121. https ://doi.org/10.1080/00016480410022787

11. Pusswald G, Auff E, Lehrner J (2012) Development of a brief selfreport inventory to measure olfactory dysfunction and quality of life in patients with problems with the sense of smell. Chemosens Percept 5:292-299. https://doi.org/10.1007/s12078-012-9127-7

12. Passali GC, Ralli M, Galli J, Calo L, Paludetti G (2008) How relevant is the impairment of smell for the quality of life in allergic rhinitis? Curr Opin Allergy Clin Immunol 8:238-242. https://doi. org/10.1097/aci.0b013e3282ffd6bb

13. Hopkins C, Surda P, Kumar N (2020) Presentation of new onset anosmia during the COVID-19 pandemic. Rhinology 58:295-298. https://doi.org/10.4193/rhin20.116

14. Hufnagl B, Lehrner J, Deecke L (2003) Development of a questionnaire for the assessment of self reported olfactory functioning. Chem Senses 28:E27. https://doi.org/10.1007/s12078-012-9127-7

15. Nordin S, Brämerson A (2008) Complaints of olfactory disorders: epidemiology, assessment and clinical implications. Curr Opin Allergy Clin Immunol 8:10-15. https://doi.org/10.1097/aci.0b013 e3282f3f473

16. Nordin S, Brämerson A, Murphy C, Bende M (2003) A Scandinavian adaptation of the Multi-Clinic Smell and Taste Questionnaire: evaluation of questions about olfaction. Acta Otolaryngol 123:536-542. https://doi.org/10.1080/00016480310001411

17. McDowell I (2006) Measuring health: a guide to rating scales and questionnaires. Oxford University Press, Oxford. https://doi. org/10.1093/acprof:oso/9780195165678.001.0001

18. Fazio AF (1977) A concurrent validational study of the NCHS General Well-Being Schedule. Vital Health Stat 2:1-53. https:// doi.org/10.1037/e409022004-001

19. Bowling A (1997) Measuring health: a review of quality of life measurement scales. Open University Press, Philadelphia. https ://doi.org/10.1046/j.1365-2648.1999.0951g.x

20. Croy I, Nordin S, Hummel T (2014) Olfactory disorders and quality of life an updated review. Chem Senses 39:185-194. https:// doi.org/10.1093/chemse/bjt072

21. Mao L, Jin H, Wang M, Hu Y, Chen S, He Q, Chang J, Hong C, Zhou Y, Wang D, Miao X (2020) Neurologic manifestations of hospitalized patients with coronavirus disease 2019 in Wuhan, China. JAMA Neurol 77:683-690. https://doi.org/10.1001/jaman eurol.2020.1127

22. Suzuki M, Saito K, Min WP, Vladau C, Toida K, Itoh H, Murakami S (2007) Identification of viruses in patients with postviral olfactory dysfunction. Laryngoscope 117:272-277. https:// doi.org/10.1097/01.mlg.0000249922.37381.1e

23. Blomqvist EH, Brämerson A, Stjarne P, Nordin S (2004) Consequences of olfactory loss and adopted coping strategies. Rhinology 42:189-194 (PubMedID: 15626250)
24. Temmel AF, Quint C, Schickinger-Fischer B, Klimek L, Stoller E, Hummel T (2002) Characteristics of olfactory disorders in relation to major causes of olfactory loss. Arch Otolaryngol Head Neck Surg 128:635-641. https://doi.org/10.1001/archotol.128.6.635

25. Nordin S, Hedén Blomqvist E, Olsson P, Stjarne P, NAF2S2 Study Group (2011) Effects of smell loss on daily life and adopted coping strategies in patients with nasal polyposis with asthma. Acta Otolaryngol 131:826-832. https://doi.org/10.3109/00016 489.2010.539625

26. Ferris AM, Duffy VB (1989) Effect of olfactory deficits on nutritional status. Does age predict persons at risk? Ann N Y Acad Sci 561:113-123. https://doi.org/10.1111/j.1749-6632.1989.tb209 75. $\mathrm{x}$

27. Miwa T, Furukawa M, Tsukatani T, Costanzo RM, DiNardo LJ, Reiter ER (2001) Impact of olfactory impairment on quality of life and disability. Arch Otolaryngol Head Neck Surg 127:497-503. https://doi.org/10.1001/archotol.127.5.497

28. Haxel BR, Nisius A, Fruth K, Mann WJ, Muttray A (2012) Deficits in medical counseling in olfactory dysfunction. HNO 60:432438. https://doi.org/10.1007/s00106-011-2448-z

29. Deems DA, Doty RL, Settle RG, Moore Gillon V, Shaman P, Mester AF, Kimmelman CP, Brightman VJ, Snow JB (1991) Smell and taste disorders, a study of 750 patients from the University of Pennsylvania Smell and Taste Center. Arch Otolaryngol Head Neck Surg 117:519-528. https://doi.org/10.1001/archo tol.1991.01870170065015

30. Frasnelli J, Hummel T (2005) Olfactory dysfunction and daily life. Eur Arch Otorhinolaryngol 262:231-235. https://doi.org/10.1007/ s00405-004-0796-y

31. Shu CH, Lee PO, Lan MY, Lee YL (2011) Factors affecting the impact of olfactory loss on the quality of life and emotional coping ability. Rhinology 49:337-341. https://doi.org/10.4193/rhino 10.130

32. Doty RL (2006) Olfactory dysfunction and its measurement in the clinic and workplace. Int Arch Occup Environ Health 79:268-282. https://doi.org/10.1007/s00420-005-0055-6

33. Croy I, Landis B, Meusel T, Seo HS, Krone F, Hummel T (2011) Patient adjustmet to reduced olfactory function. Arch Otolaryngol Head Neck Surg 137:377-382. https://doi.org/10.1001/archo to. 2011.32

Publisher's Note Springer Nature remains neutral with regard to jurisdictional claims in published maps and institutional affiliations. 